\title{
Characteristics of quinolone-resistant Escherichia coli isolated from bovine mastitis in China
}

\author{
Feng Yang, Shidong Zhang, Xiaofei Shang, Ling Wang, Hongsheng $\mathrm{Li}^{1}{ }^{1}$ and Xurong Wang ${ }^{1}$ \\ Lanzhou Institute of Husbandry and Pharmaceutical Sciences of Chinese Academy of Agricultural Science, Lanzhou 730050, \\ People's Republic of China
}

\section{ABSTRACT}

Escherichia coli is the leading causative agent of bovine mastitis worldwide. Quinolone-resistant E. coli is becoming a potential threat to veterinary and public health. The aim of this study was to investigate the characteristics of quinolone-resistant E. coli isolated from bovine mastitis cases in China. Antimicrobial susceptibility of the isolates against 15 antimicrobial agents was determined by disc diffusion method. Phylogenetic grouping was detected by PCR. Extended-spectrum $\beta$-lactamase-producing isolates were determined by double-disc synergy test. In addition, the plasmid-mediated quinolone resistance (PMQR) and $\beta$-lactamase-encoding genes, as well as mutations of quinolone resistance-determining regions in GyrA, GyrB, ParC, and ParE, were measured by PCR and DNA sequencing. Overall, $75(22.9 \%)$ out of $328 E$. coli isolates were confirmed as ciprofloxacin-resistant from 2,954 mastitic milk samples. Phylogenetic group analysis showed that the majority of these strains belonged to phylogenetic group A (57.3\%) and group B1 (24.0\%). All the resistant isolates were identified as multidrug resistant, showing high resistance to cephalosporins and non- $\beta$-lactams. Forty-nine (65.3\%) of the quinolone-resistant isolates were positive for PMQR genes; aac- $\left(6^{\prime}\right)-I b-c r$ was the most common PMQR determinant detected in $33(44.0 \%)$ isolates. Eighteen (24.0\%), 4 (5.3\%), 3 (4.0\%), and 1 (1.3\%) of the quinolone-resistant isolates were harboring oqx $A / B$, $q e p A 4, q n r S$, and qnrB2, respectively. Additionally, 55 $(73.3 \%)$ of the quinolone-resistant $E$. coli isolates were found to be extended-spectrum $\beta$-lactamase producers. The preponderant $\beta$-lactamase-encoding gene, $b l a_{\text {TEM }}$, was detected in $44(58.7 \%)$ isolates; $b l a_{\mathrm{CTX}-\mathrm{M}}, b l a_{\mathrm{CMY}}$, and $b l a_{\mathrm{SHV}}$ were found in $35(46.7 \%), 22(29.3 \%)$, and $2(2.7 \%)$ isolates, respectively. Moreover, the most

Received November 29, 2017.

Accepted February 25, 2018.

${ }^{1}$ Corresponding authors: lihsheng@sina.com and wxurong@126.com

frequently identified substitutions were S83L/D87N or S83L in GyrA, detected in all of the quinoloneresistant isolates. Meanwhile, 74 (98.7\%), 33 (44.0\%), and $6(8.0 \%)$ of the isolates were carrying substitutions S80I in ParC, S458A in ParE, and S492N in GyrB, respectively. All $58(77.3 \%)$ isolates with a high level of ciprofloxacin resistance $(>32 \mu \mathrm{g} / \mathrm{mL})$ carried single or double mutations in GyrA combined with single mutation in ParC. To the best of our knowledge, this is the first report on the high occurrence of PMQR determinants and quinolone-determining resistant regions mutations in quinolone-resistant E. coli isolated from bovine mastitis in China.

Key words: Escherichia coli, plasmid-mediated quinolone resistance, quinolone resistance-determining regions, bovine mastitis

\section{INTRODUCTION}

Bovine mastitis is the most prevalent and costly disease of dairy industry worldwide (Yang et al., 2016). Although mastitis can be caused by a variety of bacterial pathogens, Escherichia coli is one of the major causes (Zhang et al., 2016). Antibiotic therapy is the mainstay of treatment for this disease; however, the therapeutic effectiveness is limited due to the increasing incidence of antibiotic-resistant infections (Dias et al., 2013). Quinolones are potent antimicrobial agents for treatment of various infections caused by $E$. coli in veterinary medicine. Unfortunately, quinolone-resistant E. coli in food-producing animals have increased in China because of extensive usage of quinolones (Wang et al., 2008; Xiao et al., 2011; Zhao et al., 2014).

Quinolone target enzymes include DNA gyrase (GyrA and GyrB) and DNA topoisomerase IV (ParC and ParE). Both enzymes are necessary for bacterial DNA replication. Mutations in the chromosomal genes that encode quinolone target enzymes DNA gyrase or topoisomerase IV make the enzymes less sensitive to inhibition by quinolones. Multiple mutations causing AA changes in the quinolone resistance-determining regions (QRDR) of the target enzymes is the most common
\end{abstract}


mechanism of high-level quinolone resistance in clinical strains (Redgrave et al., 2014; Correia et al., 2017).

Quinolone resistance increased by harboring transferable plasmid-mediated quinolone resistance (PMQR) determinants is low compared with mutations in chromosomal genes. However, PMQR genes can transfer between bacterial interspecies at a higher frequency than chromosomal mutations, making their spread much faster than the occurrence of other types of antimicrobial resistance (Kao et al., 2016). In addition, co-resistance to $\beta$-lactams and quinolones is a common phenomenon due to the presence of $\beta$-lactamases and substitutions in QRDR, with or without PMQR genes (Bajaj et al., 2016). To date, 3 types of PMQR genes have been described: the qnr genes coding for pentapeptide to protect target enzymes DNA gyrase and topoisomerase IV from quinolone inhibition; genes $q e p A$ and $o q x A B$ coding for transporters to remove antibiotics from bacterial cells; and the gene $a a c-\left(6^{\prime}\right)-I b-c r$ coding for aminoglycoside acetyltransferase to acetylate several fluoroquinolones (Strahilevitz et al., 2009).

Although quinolone-resistant E. coli was reported worldwide, isolates from diseased food-producing ani- mals in China were limited, especially from bovine mastitis cases. The aim of our study was to characterize the quinolone-resistant E. coli isolated from bovine mastitis cases in China.

\section{MATERIALS AND METHODS}

\section{Sample Collection and Selective Cultivation of E. coli}

Mastitic milk samples of cows $(\mathrm{n}=2954)$ were obtained from 99 commercial dairy herds located in 19 provinces of China during August 2013 to September 2017 (Figure 1). After delivery to the laboratory, milk samples were inoculated onto MacConkey agar (Oxoid, Thermo Fisher Scientific, Waltham, MA) and cultivated at $37^{\circ} \mathrm{C}$ for 18 to $24 \mathrm{~h}$. Colonies with the dark pink to red colors were further confirmed by the Vitek system (BioMérieux, Marcy l'Etoile, France) according to the manufacturer's recommendations (http:// www.biomerieux-industry.com/veterinary-diagnostics/ vitek-2-technology). Ciprofloxacin susceptibility of $E$. coli isolates were determined by E-test (BioMerieux) method (0.002 to $32 \mu \mathrm{g} / \mathrm{mL}$ ) on Mueller-Hinton agar

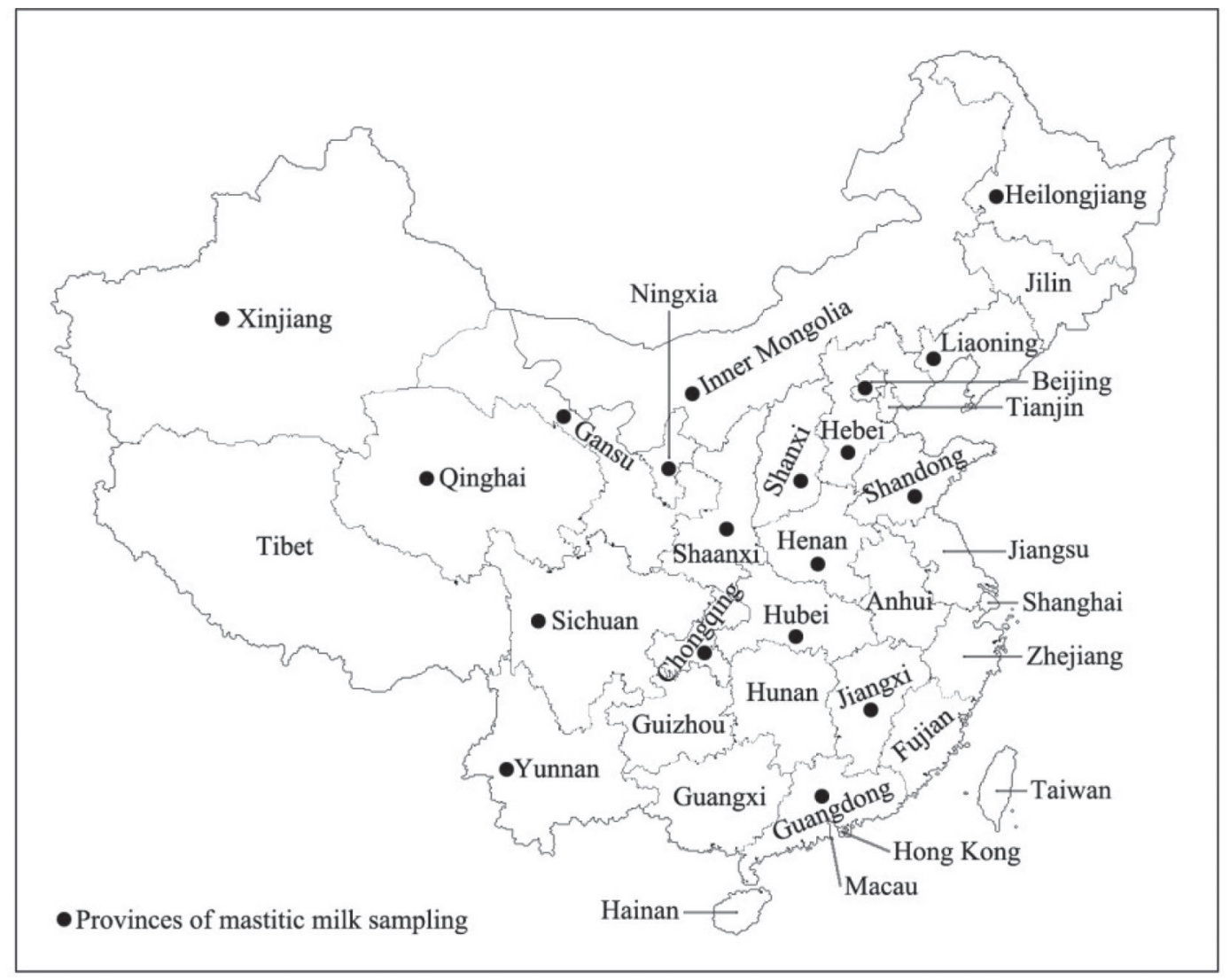

Figure 1. Sampling areas (provinces in China) involved in this study. 
Table 1. Antimicrobial susceptibility patterns of 75 quinolone-resistant Escherichia coli isolates from bovine mastitis cases

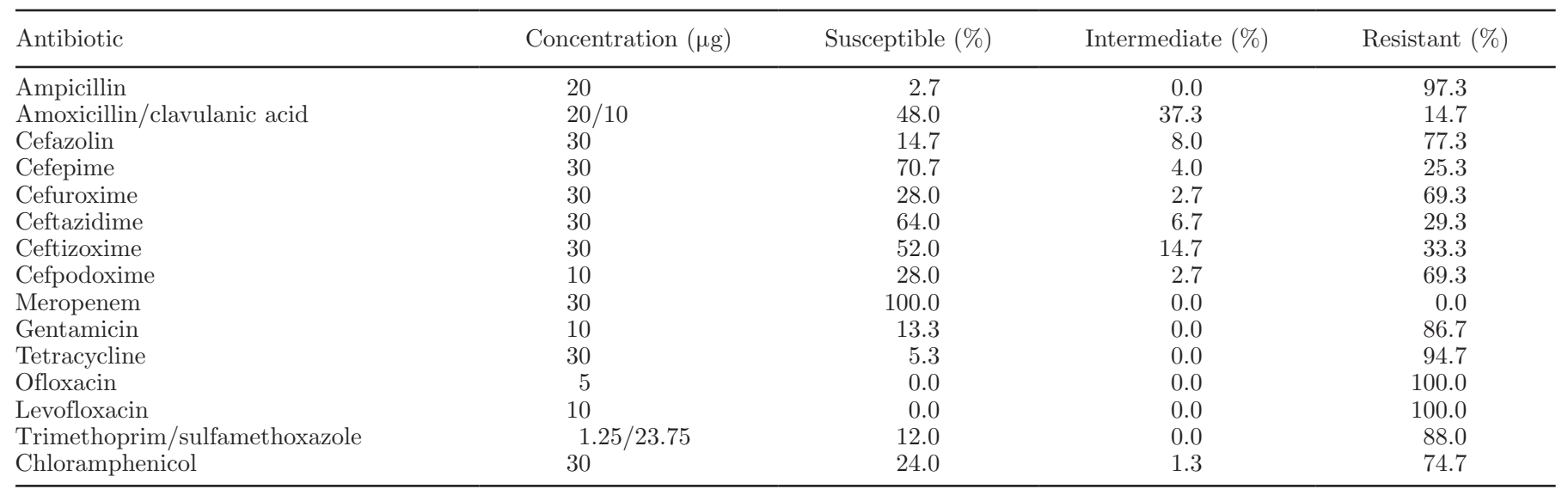

(Oxoid). A total of 75 ciprofloxacin-resistant isolates were identified according to the CLSI (2013) criteria.

\section{Antimicrobial Susceptibility Testing}

Antimicrobial susceptibility to 15 antimicrobial agents were determined by the disc diffusion method according to the recommendations of CLSI (2013). The panel of antimicrobial agents were list in Table 1. Escherichia coli ATCC 25922 and E. coli ATCC 35218 were used as quality control strains. Multidrug resistant (MDR) E. coli was defined as isolates that were resistant to at least 3 classes of the tested antimicrobial agents (Magiorakos et al., 2012).

\section{Detection of the Phylogenetic Group of E. coli Isolates}

Phylogenetic grouping of E. coli isolates was performed by PCR, as previously described (Clermont et al., 2013). Specific primers used were described in Supplemental Table S1 (https://doi.org/10.3168/jds.2017 -14156). The PCR-amplified products were separated by electrophoresis on $1.5 \%$ agarose gels and stained with ethidium bromide. Strains were assigned to 1 of 7 phylogenetic, groups A, B1, B2, C, D, E, and F, on the basis of presence and absence of corresponding DNA fragments.

\section{Detection of ESBL-Producing E. coli}

The ESBL-producing E. coli isolates were first screened by ChromID ESBL agar (BioMerieux) according to the manufacturer's recommendation (http:// www.biomerieux-diagnostics.com/chromidr-esbl). Each
E. coli isolate was aerobically incubated on ChromID ESBL agar at $37^{\circ} \mathrm{C}$ for 18 to $24 \mathrm{~h}$. Bacterial colonies showing pink to burgundy color on the agar were interpreted as ESBL-suspected strains. The presumptive ESBL-producing strains were further confirmed by double-disc synergy test with cefotaxime $(30 \mu \mathrm{g})$ and ceftazidime $(30 \mu \mathrm{g})$ alone and in combination with clavulanic acid $(10 \mu \mathrm{g})$ as recommended by CLSI (2013).

\section{Characterization of Antimicrobial Resistance Genes}

The DNA of all 75 quinolone-resistant E. coli were extracted by the Bacterial DNA Kit (Omega Bio-Tek, Norcross, GA) according to the manufacturer's recommendation (http://omegabiotek.com/store/product/ bacterial-dna-kit/). The PMQR genes $\left[a a c\left(6^{\prime}\right)-I b-c r\right.$, oqxA, oqxB,qepA, qnrA, qnrB, qnrC, qnrD, and qnrS] and $\beta$-lactamase -encoding genes $\left(b l a_{\mathrm{TEM}}, b l a_{\mathrm{CTX}-\mathrm{M}}\right.$, $b l a_{\mathrm{SHV}}, b l a_{\mathrm{DHA}}$, and $\left.b l a_{\mathrm{CMY}}\right)$ were detected by PCR amplification with specific primers (Supplemental Table S1; https://doi.org/10.3168/jds.2017-14156). Subsequently, DNA sequencing was carried out on PMQR and $\beta$-lactamase genes, and the DNA sequences were compared with genes in the GenBank database using the BLAST program (https://blast.ncbi.nlm.nih.gov/ Blast.cgi) to confirm the subtypes of antimicrobial resistance genes.

\section{Detection of QRDR Mutations in Quinolone- Resistant E. coli Isolates}

The QRDR mutations in GyrA, GyrB, ParC, and ParE genes were examined by PCR and sequencing using primers listed in Supplemental Table S1 (https:// doi.org/10.3168/jds.2017-14156). The PCR-amplified 
Table 2. Distribution of plasmid-mediated quinolone resistance (PMQR) genes and $\beta$-lactamase genes in 75 quinolone-resistant Escherichia coli isolates from bovine mastitis cases

\begin{tabular}{lc}
\hline Resistant determinant & No. of isolates \\
\hline PMQR genes & 33 \\
aac $\left(6^{\prime}\right)-I b-c r$ & 18 \\
$o q x A / B$ & $4(q e p A 4)$ \\
$q e p A$ & $1(q n r B 2)$ \\
$q n r B$ & $3(q n r S 1)$ \\
$q n r S$ & 1 \\
$o q x A+o q x B+q e p A$ & 1 \\
$a a c\left(6^{\prime}\right)-I b-c r+o q x A+o q x B+q n r S$ & 1 \\
$a a c\left(6^{\prime}\right)-I b-c r+o q x A+o q x B+q n r B+q n r S$ & \\
$\beta-l a c t a m a s e$ genes & $44\left(b l a_{\mathrm{TEM}-1}\right)$ \\
$b l a_{\mathrm{TEM}}$ & $35\left(b l a_{\mathrm{CTX}-\mathrm{M}-15}, 21 ; b l a_{\mathrm{CTX}-\mathrm{M}-55}, 14\right)$ \\
$b l a_{\mathrm{CTX}-\mathrm{M}}$ & $2\left(b l a_{\mathrm{SHV}-12}\right)$ \\
$b l a_{\mathrm{SHV}}$ & 22 \\
$b l a_{\mathrm{CMY}}$ & 16 \\
$b l a_{\mathrm{TEM}}+b l a_{\mathrm{CMY}}$ & 13 \\
$b l a_{\mathrm{CTX}-\mathrm{M}}+b l a_{\mathrm{CMY}}$ & 1 \\
$b l a_{\mathrm{CTX}-\mathrm{M}}+b l a_{\mathrm{SHV}}$ & 10 \\
$b l a_{\mathrm{TEM}}+b l a_{\mathrm{CTX}-\mathrm{M}}+b l a_{\mathrm{CMY}}$ & 1 \\
$b l a_{\mathrm{TEM}}+b l a_{\mathrm{CTX}-\mathrm{M}}+b l a_{\mathrm{SHV}}$ & \\
\hline
\end{tabular}

products were sequenced and AA mutations were evaluated using the control strain E. coli MG1655 (NC_000913.2) as a reference.

\section{Analysis of Correlation}

The correlation between antimicrobial resistance genes was assessed by one-tailed Pearson correlation (SPSS 17.0, SPSS Inc., Chicago, IL). P-value smaller than 0.05 was considered statistically significant.

\section{RESULTS}

\section{Antimicrobial Susceptibility of Quinolone- Resistant E. coli}

Overall, $328(11.1 \%)$ E. coli isolates were obtained from 2,954 mastitic milk samples from 19 provinces of China during August 2013 to September 2017, of which 75 isolates $(22.9 \%)$ were identified as ciprofloxacinresistant by the E-test method. The antimicrobial susceptibility of the 75 resistant isolates against 15 antimicrobial agents was shown in Table 1. All isolates were resistant to ofloxacin and levofloxacin. The majority of isolates were resistant to ampicillin (97.3\%), tetracycline (94.7\%), trimethoprim-sulfamethoxazole (88.0\%), gentamicin $(86.7 \%)$, cefazolin $(77.3 \%)$, chloramphenicol (74.7\%), cefuroxime (69.3\%), and cefpodoxime (69.3\%). However, we observed high susceptibility to meropenem $(100.0 \%)$, cefepime $(70.7 \%)$, ceftazidime $(64.0 \%)$, and ceftizoxime (52.0\%). Moreover, all the isolates were found to be MDR.

\section{Phylogenetic Group of Quinolone-Resistant E. coli}

The phylogenetic group analysis showed 4 groups in 75 quinolone-resistant E. coli isolates. $57.3 \%$ of the quinolone-resistant isolates belonged to phylogenetic group A, $24.0 \%$ to group B1, $9.3 \%$ to group B2, and $9.3 \%$ belonged to group $\mathrm{D}$.

\section{Characterization of Antimicrobial Resistance Genes}

The frequency of PMQR genes $\left[a a c\left(6^{\prime}\right)-I b-c r, q e p A\right.$, $o q x A, o q x B$, and $q n r$ alleles] were determined by PCR and sequencing (Table 2). The results showed that 49 quinolone-resistant isolates $(65.3 \%)$ carried at least 1 PMQR gene. Genes $a a c\left(6^{\prime}\right)-I b-c r$ and $o q x A / B$ were found in 44.0 and $24.0 \%$ of the isolates, respectively; $q e p A 4, q n r B 2$, and $q n r S 1$ were identified in 5.3, 1.3, and $4.0 \%$ of the isolates, respectively. Notably, 1 isolate harbored 5 PMQR genes $\left[a a c\left(6^{\prime}\right)-I b-c r\right.$, oqxA, oqxB, qnrB2, and $q n r S 1]$ in combination, 1 harbored $4 \mathrm{PMQR}$ genes $\left[a a c\left(6^{\prime}\right)-I b-c r, o q x A, o q x B\right.$, and $\left.q n r S 1\right]$, and 1 harbored 3 PMQR genes (oqxA, oqxB, and qepA4). The qnr alleles, including $q n r A, q n r C$, qnrD, and $q n r V C$, were not found in any of the isolates.

The double-disc synergy test revealed that $73.3 \%$ of the E. coli isolates were ESBL producers. The frequency of $\beta$-lactamase-encoding genes among the 75 quinolone-resistant isolates are shown in Table 2. The dominant $\beta$-lactamase gene was $b l a_{\text {TEM }}(58.7 \%)$, followed by $b l a_{\mathrm{CTX-M}}(46.7 \%), b l a_{\mathrm{CMY}-2}(29.3 \%)$, and $b l a_{\mathrm{SHV}}$ $(2.7 \%)$. Sequence analysis revealed that all $44 b l a_{\text {TEM }}$ type $\beta$-lactamase were identified as $b l a_{\mathrm{TEM}-1}$, and 21 $b l a_{\mathrm{CTX}-\mathrm{M}-15}$ and $14 b l a_{\mathrm{CTX}-\mathrm{M}-55}$ were confirmed among the 
$35 b l a_{\mathrm{CTX}-\mathrm{M}}$ type $\beta$-lactamase, respectively. The $2 b l a_{\mathrm{SHV}}$ genes were identified as $b l a_{\mathrm{SHV}-12}$. Moreover, the coexistence of $b l a_{\text {TEM }}$ and $b l a_{\mathrm{CMY}}(21.3 \%)$ were most frequently observed, followed by $b l a_{\text {CTX-M }}$ and $b l a_{\mathrm{CMY}}(17.3 \%)$ and $b l a_{\mathrm{CTX}-\mathrm{M}}$ and $b l a_{\mathrm{SHV}}(1.3 \%)$. Notably, $14.7 \%$ of the isolates carried $3 \beta$-lactamase genes (bla $a_{\mathrm{TEM}}, b l a_{\mathrm{CTX}-\mathrm{M}}$, and $b l a_{\mathrm{CMY}}, 13.3 \%$; $b l a_{\mathrm{TEM}}, b l a_{\mathrm{CTX}-\mathrm{M}}$, and $\left.b l a_{\mathrm{SHV}}, 1.3 \%\right)$ in combination.

The most abundant antimicrobial resistance genes found in our study were PMQR genes aac $\left(6^{\prime}\right)-I b-c r$, $o q x A$, and $o q x B$, as well as the $\beta$-lactam resistance genes $b l a_{\mathrm{TEM}}, b l a_{\mathrm{CTX}-\mathrm{M}}$, and $b l a_{\mathrm{CMY}}$. The correlation between these genes showed that PMQR genes oqxA and oqxB were significantly $(P<0.05)$ correlated. Moreover, significant correlations $(P<0.05)$ were found between $a a c\left(6^{\prime}\right)-I b-c r$ and $b l a_{\mathrm{CMY}}$ (Supplemental Table S2; https://doi.org/10.3168/jds.2017-14156).

\section{QRDR Mutations in Quinolone-Resistant E. coli Isolates}

Mutations of QRDR in GyrA, GyrB, ParC, and ParE of the 75 quinolone-resistant $E$. coli isolates were determined by PCR and sequencing (Table 3). The results showed that no isolate with wild-type GyrA was observed. The most common point mutations in the strains were S83L/D87N (88.0\%) and S83L (12.0\%) in GyrA, followed by S80I (98.7\%) in ParC, S458A $(44.0 \%)$ in ParE, and S492N (8.0\%) in GyrB. All the isolates $(77.3 \%)$ with high-level ciprofloxacin resistance $(>32 \mu \mathrm{g} / \mathrm{mL})$ carried single or double mutations in GyrA combined with a single mutation in ParC.

\section{DISCUSSION}

Quinolones are important antimicrobial agents widely used in veterinary and human medicine. In the past few years, quinolone resistance in gram-negative bacteria has been on the rise worldwide, particularly in E. coli (Robicsek et al., 2006; Xiao et al., 2011; Machuca et al., 2017). We reported a similar occurrence $(22.9 \%)$ of quinolone-resistant $E$. coli among 328 E. coli from bovine mastitis cases, as compared with previous studies about dairy cattle suffering mastitis $(22.4 \%)$ and endometritis $(25.0 \%)$ in China (Wang et al., 2008; Zhao et al., 2014). However, our result was much higher than data from developed countries, where the reported prevalence of quinolone-resistant E. coli in bovine mastitis cases were $0.7 \%$ for Finland and $0.0 \%$ for both Canada and the United States (Suojala et al., 2011; Saini et al., 2012; Metzger and Hogan, 2013). Xiao et al. (2011) presumed that widespread addition of quinolones to animal feed was associated with the high rates of quinolone resistance in China. In China, quinolones such as ciprofloxacin are permitted to be used for antimicrobial therapy in veterinary medicine (MOA 2013); however, use of quinolones in livestock has already been limited or banned in the developed countries (Pol and Ruegg, 2007; Swinkels et al., 2015; Kuipers et al., 2016). Thus, the disparity in quinolone resistance between isolates from China as compared with other countries may indicate that long-term and widespread use of this class of antimicrobials in livestock has contributed to a greater prevalence of antimicrobial resistance, at least among $E$. coli isolates. Moreover, our results found that all quinolone-resistant

Table 3. Minimum inhibitory concentrations, plasmid-mediated quinolone resistance (PMQR) genes, and quinolone resistance-determining regions (QRDR) mutations of 75 quinolone-resistant Escherichia coli isolates

\begin{tabular}{|c|c|c|c|c|c|c|}
\hline Isolate & $\begin{array}{l}\text { Ciprofloxacin } \\
\text { MIC }(\mu \mathrm{g} / \mathrm{mL})\end{array}$ & PMQR genes & \multicolumn{4}{|c|}{ QRDR mutations ${ }^{1}$} \\
\hline CR 2 & 6 & $a a c\left(6^{\prime}\right) I b-c r$ & S83L,D87N & - & S80I & - \\
\hline CR 3 & $>32$ & $a a c\left(6^{\prime}\right) I b-c r, o q x A / B$ & S83L,D87N & - & S80I & - \\
\hline CR 4 & $>32$ & $-^{2}-2+2+3$ & S83L,D87N & - & S80I & S458A \\
\hline CR 5 & $>32$ & qepA4 & S83L,D87N & - & S80I & S458A \\
\hline CR 8 & $>32$ & $a a c\left(6^{\prime}\right) I b-c r$ & S83L,D87N & - & S80I & S458A \\
\hline CR 9 & $>32$ & - & S83L,D87N & S492N & S80I & - \\
\hline CR 10 & 6 & - & S83L,D87N & - & S80I & - \\
\hline CR 11 & $>32$ & - & S83L,D87N & S492N & S80I & - \\
\hline CR 12 & $>32$ & $a a c\left(6^{\prime}\right) I b-c r$ & $\mathrm{~S} 83 \mathrm{~L}, \mathrm{D} 87 \mathrm{~N}$ & - & S80I & - \\
\hline CR 13 & $>32$ & oqxA/B, qерA4 & S83L,D87N & - & S80I & - \\
\hline CR 14 & $>32$ & $o q x A / B$ & S83L,D87N & - & S80I & - \\
\hline
\end{tabular}


Table 3 (Continued). Minimum inhibitory concentrations, plasmid-mediated quinolone resistance (PMQR) genes, and quinolone resistancedetermining regions (QRDR) mutations of 75 quinolone-resistant Escherichia coli isolates

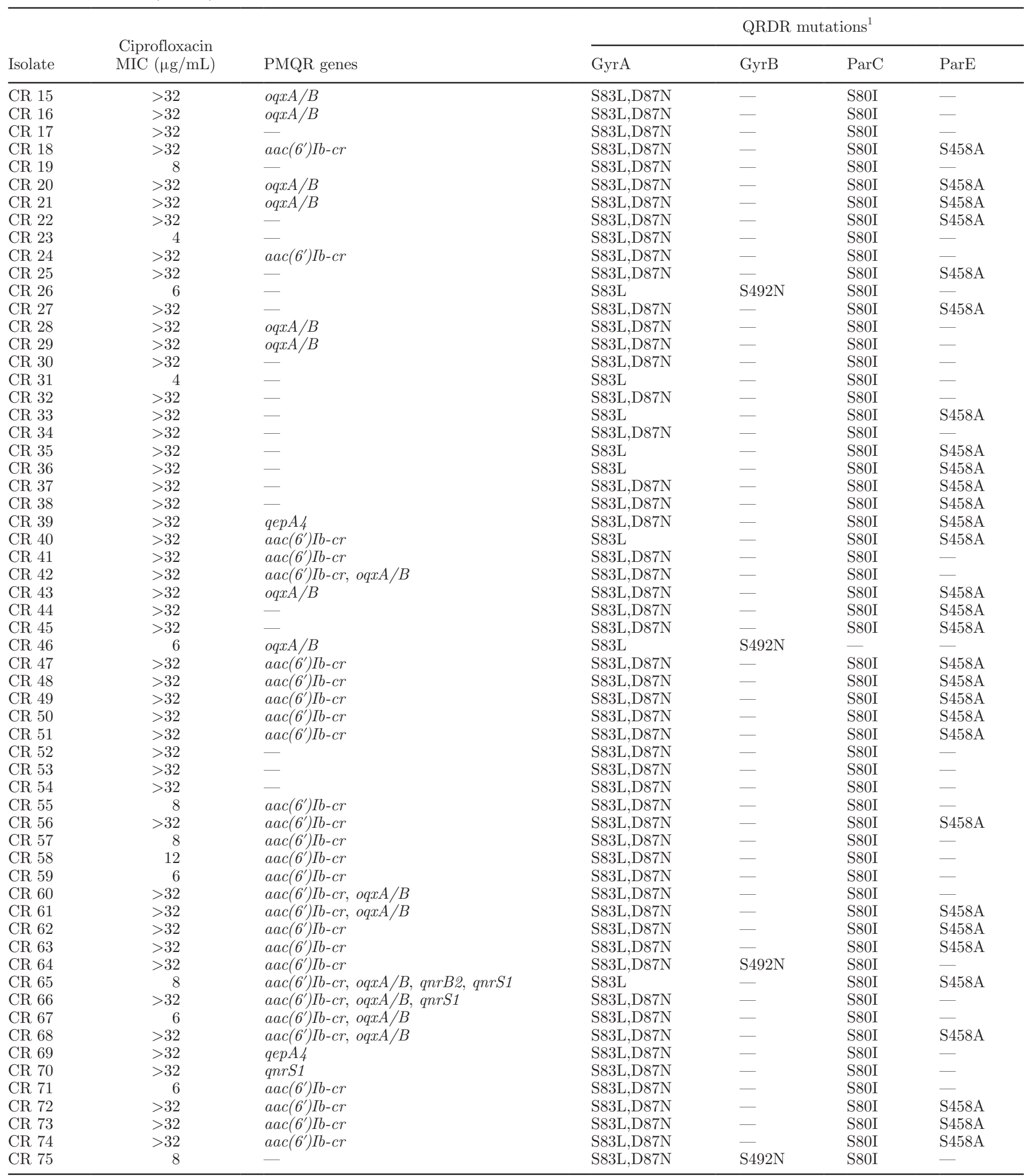

${ }^{1}$ QRDR of E. coli MG1655 (NC_000913.2) as a wild-type reference.

${ }^{2}$ Isolates with no PMQR genes or QRDR mutations. 
E. coli isolates were MDR, which is in accordance to the previous studies in China (Zhang et al., 2012; Ali et al., 2016). The E. coli isolates showed high resistance to ampicillin, tetracycline, trimethoprim-sulfamethoxazole, gentamicin, cefazolin, chloramphenicol, cefuroxime, and cefpodoxime, agreeing with previous studies in China and other countries (Lei et al., 2010; Jones-Dias et al., 2013; Begum et al., 2016). The high-level resistance among the $E$. coli isolates may reflect the general use of antimicrobials in dairy cows in China (Swinkels et al., 2015). Thus, governmental agencies should pay more attention to critically supervise antibiotics usage, as the frequent occurrence of resistant isolates pose a serious threat to public health through the food chain (Kilani et al., 2015).

The phylogenetic group B2 and group D were the most common virulent extraintestinal E. coli in many countries, whereas most commensal strains belong to groups A and B1 (Clermont et al., 2000). Our results showed that most of the quinolone-resistant E. coli isolates belonged to groups A $(57.3 \%)$ and B1 (24.0\%). Similar results were reported that $E$. coli isolates associated with mastitis mainly belonged to groups B1 and A in China (Liu et al., 2014; Ali et al., 2016); these studies have given us a better understanding of the importance of environmental $E$. coli in bovine mastitis cases.

We found that $65.3 \%$ of quinolone-resistant E. coli isolates contained PMQR genes. The dominant PMQR genes among these strains were $a a c\left(6^{\prime}\right)-I b-c r(44.0 \%)$ and $o q x A / B(24.0 \%)$, whereas qepA, qnrB and qnrS were detected with lower frequencies. Similar reports regarding $\mathrm{PMQR}$ genes have been published in previous studies (Zurfluh et al., 2014; Zhao et al., 2015; Osei Sekyere and Amoako, 2017). These findings suggest that $a a c\left(6^{\prime}\right)-I b-c r$ and $o q x A / B$ play a major role in plasmid-mediated quinolone resistance in $E$. coli from bovine mastitis in China.

$\beta$-Lactamase genes are frequently found together with quinolone resistance genes (Schultsz and Geerlings 2012 ). Our results showed that $73.3 \%$ of the quinoloneresistant E. coli isolates were identified as ESBL producers. In addition, the predominant $\beta$-lactamase gene in the quinolone-resistant isolates was $b l a_{\text {TEM }}(58.7 \%)$, followed by $b l a_{\text {СтХ-м }}(46.7 \%)$, bla $a_{\text {CMY }}(29.3 \%)$, and $b l a_{\mathrm{SHV}}(2.7 \%)$. These findings agree with other contemporary studies that also reported these $\beta$-lactamase genes were frequently observed in quinolone-resistant E. coli isolates (Ma et al., 2009; Park et al., 2012; Yan et al., 2017). Moreover, our results were in accord with previous studies and confirmed that CTX-M-15 was the most common CTX-M $\beta$-lactams in E. coli from bovine mastitis (Ohnishi et al., 2013; Ali et al., 2016; Tark et al., 2017). The correlation analysis between PMQR genes and $\beta$-lactamase genes showed only aac $\left(6^{\prime}\right)-\mathrm{Ib}$-cr and $b l a_{\mathrm{CMY}}$ were significant correlated, which suggest that the co-existence of resistance to quinolones and $\beta$-lactams is not yet epidemic in bovine mastitis cases in China.

Strains of food-producing animals with mutations in DNA gyrase (GyrA and GyrB) and DNA topoisomerase IV (ParC and ParE) have been reported worldwide (Röderova et al., 2017). Quinolone resistance arises initially through mutations of GyrA, and additional mutation of ParC leads to highly resistant E. coli. Topoisomerase IV acts as a secondary target (Pan and Fisher, 1996). Our results were in line with previous studies that reported point mutations in quinoloneresistant E. coli happened more frequently in S83L/ D87N (88.0\%) and S83L (12.0\%) in GyrA and S80I $(98.7 \%)$ in ParC (Yue et al., 2008; Morgan-Linnell et al., 2009; Bansal and Tandon, 2011; Hu et al., 2017). Moreover, in our study, all quinolone-resistant isolates with high-level ciprofloxacin resistance (>32 mg/L) carried single or double mutations in GyrA combined with single mutation in ParC, as described previously (Röderova et al., 2017). These findings indicate that mutations in GyrA and ParC may contribute to the high-level of quinolone resistance in $E$. coli isolated from bovine mastitis cases in China, and the specific mechanisms should be studied further.

Zhao et al. (2014) reported that P385A substitution of GyrB was found in all resistant isolates from dairy cattle in China. However, in our study, only $8.0 \%$ of the E. coli strains carried substitutions of GyrB at position S492N. Nevertheless, similar substitution of GyrB was observed in ESBL- or AmpC-producing E. coli from India, although mutations in GyrB subunit of DNA gyrase in clinical $E$. coli had a less significant association with quinolone resistance (Bajaj et al., 2016). Similar to our study, lines of investigations had reported the substitutions of ParE at position S458A in clinical E. coli isolates (Liu et al., 2012; Zhao et al., 2014; Zurfluh et al., 2014; Del Rio-Avila et al., 2016). Likewise, we found all of the substitutions of ParE at position S485A (44. 0\%) to be present in high levels of ciproflxacinresistant strains combined with substitutions in GryA and ParC. These findings suggest that the substitution at position 458 of ParE appears to confer high-level quinolone resistance. However, the contribution of this mutation needs to be investigated in greater details because the position lies outside of the QRDR of ParE (Bajaj et al., 2016).

\section{CONCLUSIONS}

In summary, in response to frequent resistance against most antimicrobials in E. coli isolates from bovine mastitis, more comprehensive surveillance of antimicrobial 
agent usage in livestock in China is required. Although the coordinated expression of major PMQR genes and $\beta$-lactam resistance genes is not yet a widespread phenomenon, the PMQR- and $\beta$-lactamase-encoding genes are highly prevalent in quinolone-resistant $E$. coli. In addition, high occurrence of QRDR mutations in DNA gyrase GyrA and DNA topoisomerase IV ParC suggests that both of the enzymes may play a key role as a quinolone target in $E$. coli recovered from bovine mastitis in China. To the best of our knowledge, this is the first report on the high occurrence of PMQR determinants and QRDR mutations in quinolone-resistant E. coli isolates from bovine mastitis in China.

\section{ACKNOWLEDGMENTS}

This work was supported by the Special Fund of Chinese Central Government for Basic Scientific Research Operations in Commonweal Research Institutes (No. 1610322017013) and the National Key Research and Development Program of China (No. 2017YFD0502200).

\section{REFERENCES}

Ali, T., S. Ur Rahman, L. Zhang, M. Shahid, S. Zhang, G. Liu, J. Gao, and B. Han. 2016. ESBL-producing Escherichia coli from cows suffering mastitis in china contain clinical class 1 integrons with CTX-M linked to ISCR1. Front. Microbiol. 7:1931.

Bajaj, P., P. K. Kanaujia, N. S. Singh, S. Sharma, S. Kumar, and J. S. Virdi. 2016. Quinolone co-resistance in ESBL- or AmpC-producing Escherichia coli from an Indian urban aquatic environment and their public health implications. Environ. Sci. Pollut. Res. Int. 23:1954-1959.

Bansal, S., and V. Tandon. 2011. Contribution of mutations in DNA gyrase and topoisomerase IV genes to ciprofloxacin resistance in Escherichia coli clinical isolates. Int. J. Antimicrob. Agents 37:253-255.

Begum, Y. A., K. A. Talukder, I. J. Azmi, M. Shahnaij, A. Sheikh, S. Sharmin, A. M. Svennerholm, and F. Qadri. 2016. Resistance pattern and molecular characterization of enterotoxigenic Escherichia coli (ETEC) strains isolated in Bangladesh. PLoS One 11:e0157415.

Clermont, O., S. Bonacorsi, and E. Bingen. 2000. Rapid and simple determination of the Escherichia coli phylogenetic group. Appl. Environ. Microbiol. 66:4555-4558.

Clermont, O., J. K. Christenson, E. Denamur, and D. M. Gordon. 2013. The clermont Escherichia coli phylo-typing method revisited: improvement of specificity and detection of new phylo-groups. Environ. Microbiol. Rep. 5:58-65.

CLSI. 2013. Performance standards for antimicrobial susceptibility testing. CLSI document M100-S23. Clinical and Laboratory Standard Institute (CLSI), Wayne, PA..

Correia, S., P. Poeta, M. Hébraud, J. L. Capelo, and G. Igrejas. 2017. Mechanisms of quinolone action and resistance: Where do we stand? J. Med. Microbiol. 66:551-559.

Del Rio-Avila, C., C. Rosario, S. Arroyo-Escalante, E. M. CarrilloCasas, E. Díaz-Aparicio, F. Suarez-Güemes, J. Silva-Sanchez, J. Xicohtencatl-Cortes, P. Maravilla, and R. Hernández-Castro. 2016. Characterisation of quinolone-resistant Escherichia coli of 1997 and 2005 isolates from poultry in Mexico. Br. Poult. Sci. $57: 494-500$.

Dias, R. S., M. R. Eller, V. S. Duarte, Â. L. Pereira, C. C. Silva, H. C. Mantovani, L. L. Oliveira, E. A. Silva, and S. O. De Paula. 2013.
Use of phages against antibiotic-resistant Staphylococcus aureus isolated from bovine mastitis. J. Anim. Sci. 91:3930-3939.

Hu, Y. S., S. Shin, Y. H. Park, and K. T. Park. 2017. Prevalence and mechanism of fluoroquinolone resistance in Escherichia coli isolated from swine feces in Korea. J. Food Prot. 80:1145-1151.

Jones-Dias, D., V. Manageiro, A. P. Francisco, A. P. Martins, G. Domingues, D. Louro, E. Ferreira, and M. Caniça. 2013. Assessing the molecular basis of transferable quinolone resistance in Escherichia coli and Salmonella spp. from food-producing animals and food products. Vet. Microbiol. 167:523-531.

Kao, C. Y., H. M. Wu, W. H. Lin, C. C. Tseng, J. J. Yan, M. C. Wang, C. H. Teng, and J. J. Wu. 2016. Plasmid-mediated quinolone resistance determinants in quinolone-resistant Escherichia coli isolated from patients with bacteremia in a university hospital in Taiwan, 2001-2015. Sci. Rep. 6:32281.

Kilani, H., M. S. Abbassi, S. Ferjani, R. Mansouri, S. Sghaier, R. Ben Salem, I. Jaouani, G. Douja, S. Brahim, S. Hammami, N. Ben Chehida, and I. B. Boubaker. 2015. Occurrence of bla $a_{\mathrm{CTX} \text {-M-1, }}$, qnrB1 and virulence genes in avian ESBL-producing Escherichia coli isolates from Tunisia. Front. Cell. Infect. Microbiol. 5:38.

Kuipers, A., W. J. Koops, and H. Wemmenhove. 2016. Antibiotic use in dairy herds in the Netherlands from 2005 to 2012. J. Dairy Sci. 99:1632-1648.

Lei, T., W. Tian, L. He, X. Huang, Y. Sun, Y. Deng, Y. Sun, D. Lv, C. Wu, L. Huang, J. Shen, and J. Liu. 2010. Antimicrobial resistance in Escherichia coli isolates from food animals, animal food products and companion animals in China. Vet. Microbiol. 146:85-89.

Liu, X., D. M. Boothe, K. Thungrat, and S. Aly. 2012. Mechanisms accounting for fluoroquinolone multidrug resistance Escherichia coli isolated from companion animals. Vet. Microbiol. 161:159-168.

Liu, Y., G. Liu, W. Liu, Y. Liu, T. Ali, W. Chen, J. Yin, and B. Han. 2014. Phylogenetic group, virulence factors and antimicrobial resistance of Escherichia coli associated with bovine mastitis. Res. Microbiol. 165:273-277.

Ma, J., Z. L. Zeng, Z. L. Chen, X. G. Xu, X. Y. Wang, Y. T. Deng, D. H. Lu, L. Z. Huang, Y. Y. Zhang, and J. H. Liu. 2009. High prevalence of plasmid-mediated quinolone resistance determinants $q n r, a a c\left(6^{\prime}\right)-I b-c r$, and qepA among ceftiofur-resistant Enterobacteriaceae isolates from companion and food-producing animals. Antimicrob. Agents Chemother. 53:519-524.

Machuca, J., E. Recacha, A. Briales, P. Díazdealba, J. Blazquez, and Á. Pascual. 2017. Cellular response to ciprofloxacin in low-level quinolone-resistant Escherichia coli. Front. Microbiol. 8:1370.

Magiorakos, A. P., A. Srinivasan, R. B. Carey, Y. Carmeli, M. E. Falagas, C. G. Giske, S. Harbarth, J. F. Hindler, G. Kahlmeter, and B. Olssonliljequist. 2012. Multidrug-resistant, extensively drugresistant and pandrug-resistant bacteria: An international expert proposal for interim standard definitions for acquired resistance. Clin. Microbiol. Infect. 18:268-281.

Metzger, S. A., and J. S. Hogan. 2013. Short communication: Antimicrobial susceptibility and frequency of resistance genes in Escherichia coli isolated from bovine mastitis. J. Dairy Sci. 96:30443049 .

MOA. 2013. Ministry of Agriculture of the People's Republic of China. Announcement No.1997 of the Ministry of Agriculture. Accessed Jan. 17, 2018. http://www.moa.gov.cn/fwllm/zxbs/xzxk/spyj/ 201706/t20170606_5662448.htm.

Morgan-Linnell, S. K., L. B. Boyd, D. Steffen, and L. Zechiedrich. 2009. Mechanisms accounting for fluoroquinolone resistance in Escherichia coli clinical isolates. Antimicrob. Agents Chemother. 53:235-241.

Ohnishi, M., A. T. Okatani, K. Harada, T. Sawada, K. Marumo, M. Murakami, R. Sato, H. Esaki, K. Shimura, and H. Kato. 2013. Genetic characteristics of CTX-M-type extended-spectrum- $\beta$ Lactamase (ESBL)-producing Enterobacteriaceae involved in mastitis cases on Japanese dairy farms, 2007 to 2011. J. Clin. Microbiol. 51:3117-3122.

Osei Sekyere, J., and D. G. Amoako. 2017. Genomic and phenotypic characterisation of fluoroquinolone resistance mechanisms in Enterobacteriaceae in Durban, South Africa. PLoS One 12:e0178888. 
Pan, X. S., and L. M. Fisher. 1996. Cloning and characterization of the parC and parE genes of Streptococcus pneumoniae encoding DNA topoisomerase IV: Role in fluoroquinolone resistance. J. Bacteriol. 178:4060-4069.

Park, K. S., M. H. Kim, T. S. Park, S. N. You, H. J. Lee, and T. S. Jin. 2012. Prevalence of the plasmid-mediated quinolone resistance genes, $a a c\left(6^{\prime}\right)-I b-c r$, qep $A$, and $o q x A B$ in clinical isolates of extended-spectrum $\beta$-Lactamase (ESBL)-producing Escherichia coli and Klebsiella pneumoniae in Korea. Ann. Clin. Lab. Sci. 42:191-197.

Pol, M., and P. L. Ruegg. 2007. Treatment practices and quantification of antimicrobial drug usage in conventional and organic dairy farms in Wisconsin. J. Dairy Sci. 90:249-261.

Redgrave, L. S., S. B. Sutton, M. A. Webber, and L. J. Piddock. 2014. Fluoroquinolone resistance: mechanisms, impact on bacteria, and role in evolutionary success. Trends Microbiol. 22:438-445.

Robicsek, A., G. A. Jacoby, and D. C. Hooper. 2006. The worldwide emergence of plasmid-mediated quinolone resistance. Lancet Infect. Dis. 6:629-640.

Röderova, M., D. Halova, I. Papousek, M. Dolejska, M. Masarikova, V. Hanulik, V. Pudova, P. Broz, M. Htoutousedlakova, and P. Sauer. 2017. Characteristics of quinolone resistance in Escherichia coli isolates from humans, animals, and the environment in the Czech Republic. Front. Microbiol. 7:2147.

Saini, V., J. T. McClure, D. Léger, G. P. Keefe, D. T. Scholl, D. W. Morck, and H. W. Barkema. 2012. Antimicrobial resistance profiles of common mastitis pathogens on Canadian dairy farms. J. Dairy Sci. 95:4319-4332.

Schultsz, C., and S. Geerlings. 2012. Plasmid-mediated resistance in Enterobacteriaceae. Drugs 72:1-16.

Strahilevitz, J., G. A. Jacoby, D. C. Hooper, and A. Robicsek. 2009. Plasmid-mediated quinolone resistance: A multifaceted threat. Clin. Microbiol. Rev. 22:664-689.

Suojala, L., T. Pohjanvirta, H. Simojoki, A. L. Myllyniemi, A. Pitkälä, S. Pelkonen, and S. Pyörälä. 2011. Phylogeny, virulence factors and antimicrobial susceptibility of Escherichia coli isolated in clinical bovine mastitis. Vet. Microbiol. 147:383-388.

Swinkels, J. M., A. Hilkens, V. Zoche-Golob, V. Krömker, M. Buddiger, J. Jansen, and T. J. Lam. 2015. Social influences on the duration of antibiotic treatment of clinical mastitis in dairy cows. J. Dairy Sci. 98:2369-2380.

Tark, D. S., D. C. Moon, H. Y. Kang, S. R. Kim, H. M. Nam, H. S. Lee, S. C. Jung, and S. K. Lim. 2017. Antimicrobial susceptibility and characterization of extended-spectrum $\beta$-lactamases in Escherichia coli isolated from bovine mastitic milk in South Korea from 2012 to 2015. J. Dairy Sci. 100:3463-3469.

Wang, G. Q., C. M. Wu, X. D. Du, Z. Q. Shen, L. H. Song, X. Chen, and J. Z. Shen. 2008. Characterization of integrons-mediated antimicrobial resistance among Escherichia coli strains isolated from bovine mastitis. Vet. Microbiol. 127:73-78.

Xiao, Y. H., C. G. Giske, Z. Q. Wei, P. Shen, A. Heddini, and L. J. Li. 2011. Epidemiology and characteristics of antimicrobial resistance in China. Drug Resist. Updat. 14:236-250.

Yan, L., D. Liu, X. H. Wang, Y. Wang, B. Zhang, M. Wang, and H. $\mathrm{Xu}$. 2017. Bacterial plasmid-mediated quinolone resistance genes in aquatic environments in China. Sci. Rep. 7:40610.

Yang, F., L. H. Liu, X. P. Li, J. Y. Luo, Z. Zhang, Z. T. Yan, S. D. Zhang, and H. S. Li. 2016. Short communication: N-Acetylcysteine-mediated modulation of antibiotic susceptibility of bovine mastitis pathogens. J. Dairy Sci. 99:4300-4302.

Yue, L., H. X. Jiang, X. P. Liao, J. H. Liu, S. J. Li, X. Y. Chen, C. X. Chen, D. H. Lü, and Y. H. Liu. 2008. Prevalence of plasmid-mediated quinolone resistance $q n r$ genes in poultry and swine clinical isolates of Escherichia coli. Vet. Microbiol. 132:414-420.

Zhang, Y., Y. J. Yang, L. Ye, Y. Luo, W. Wang, W. Zhou, Z. Cui, and L. Han. 2012. Characterization of clinical multidrug-resistant Escherichia coli and Klebsiella pneumoniae isolates, 2007-2009, China. Microb. Drug Resist. 18:465-470.

Zhang, Z., X. P. Li, F. Yang, J. Y. Luo, X. R. Wang, L. H. Liu, and H. S. Li. 2016. Influences of season, parity, lactation, udder area, milk yield, and clinical symptoms on intramammary infection in dairy cows. J. Dairy Sci. 99:6484-6493.

Zhao, H. X., J. L. Zhao, J. Z. Shen, H. L. Fan, H. Guan, X. P. An, and P. F. Li. 2014. Prevalence and molecular characterization of fluoroquinolone resistance in Escherichia coli isolates from dairy cattle with endometritis in China. Microb. Drug Resist. 20:162-169.

Zhao, L., J. Zhang, B. Zheng, Z. Wei, P. Shen, S. Li, L. Li, and Y. Xiao. 2015. Molecular epidemiology and genetic diversity of fluoroquinolone-resistant Escherichia coli isolates from patients with community-onset infections in 30 Chinese county hospitals. J. Clin. Microbiol. 53:766-770.

Zurfluh, K., H. Abgottspon, H. Hächler, M. Nüeschinderbinen, and R. Stephan. 2014. Quinolone resistance mechanisms among extendedspectrum beta-lactamase (ESBL) producing Escherichia coli isolated from rivers and lakes in Switzerland. PLoS One 9:e95864. 